\section{Balzan-Preis 1990}

\section{Für Humanität, Frieden und Brüderlichkeit unter den Völkern}

\section{Für Altertumswissenschaften (Mittelmeerraum)}

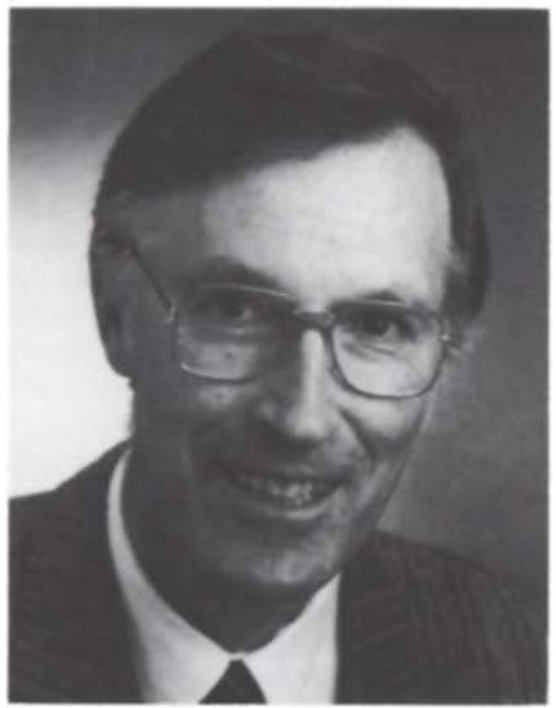

Walter Burkert. Für herausragende Forschung auf dem Gebiet der antiken Religionen. In einer Reihe von grundlegenden Schriften verbindet er Originalität mit meisterhafter Beherrschung aller einschlägigen Zeugnisse, von der Archäologie des Mittleren Ostens bis zur griechischen Philosophiegeschichte, und besticht durch profunde Kenntnis der anthropologischen, ethologischen und psychologischen Aspekte der Religion.

Über den Balzan-Preis. Die „Internationale Balzan-Stiftung“, gegründet 1956 auf Veranlassung von Frau Angela Lina Balzan und finanziert aus dem Vermögen ihres Vaters, strebt an: "In der ganzen Welt die Kultur, die Wissenschaften und besonders verdienstvolle humanitäre Leistungen für Frieden und Brüderlichkeit unter den Völkern, ohne Ansehen von Nationalität, Rasse und Religionszugehörigkeit, zu fördern." Die Stiftung verleiht Preise für Geistes- und Sozialwissenschaften, Kunst, Physik, Mathematik, Naturwissenschaften und Medizin sowie einen Preis für Humanität, Frieden und Brüderlichkeit unter den Völkern. Die Stiftung wirkt in der Praxis durch zwei Stiftungen, eine italienischen Rechts - die Stiftung "Preis“ - , die andere schweizerischen Rechts - die Stiftung „Fonds“ - , die im engsten Zusammenwirken ihr gemeinsames Ziel anstreben. Die Stiftung „Preis“ wird von einem international zusammengesetzten Preisverleihungskomitee geleitet, das die Empfänger der Preise bestimmt; der Stiftung „Fonds“ steht ein Stiftungsrat vor, der sich in erster Linie um die Sicherung des Stiftungsvermögens kümmert.

Die bisherigen Preisträger sind: Nobel-Stiftung (1961), Papst Johannes XXIII., Karl von Frisch, Andrej Kolmogorov, Paul Hindemith, Samuel Eliot Morison (1962), Mutter Theresa (1978), Jean Piaget, Ernest Labrousse, Giuseppe Tucci, Torbjörn Caspersson (1979), Enrico Bombieri, Jorge Luis Borges, Hassan Fathy (1980), Josef Pieper, Paul Reuter, Dan Peter McKenzie, Drummond Hoyle Matthews, Frederick John Vine (1981), Jean-Baptiste Duroselle, Massimo Pallottino, Kenneth Vivian Thimann (1982), Francesco Gabrieli, Ernst Mayr, Edward Shils (1983), Jan Hendrik Oort, Sewall Wright, Jean Starobinski (1984), Jean-Pierre Serre, Sir Ernst Hans Josef Gombrich (1985), Hochkommissariat der Vereinten Nationen für Flüchtlingshilfe, Otto Neugebauer, Roger Revelle, Jean Rivero (1986), Jerome Seymour Bruner, Phillip V. Tobias, Sir Richard William Southern (1987), Michael Evenari, Otto Ludwig Lange, René Ernest Joseph Eugène Étiemble, Shmuel N. Eisenstadt (1988), Martin John Rees, Leo Pardi, Emmanuel Lévinas (1989). 1990 sind die Preise mit jeweils 300000 Schweizer Franken dotiert.

\section{Für Internationales Privatrecht}

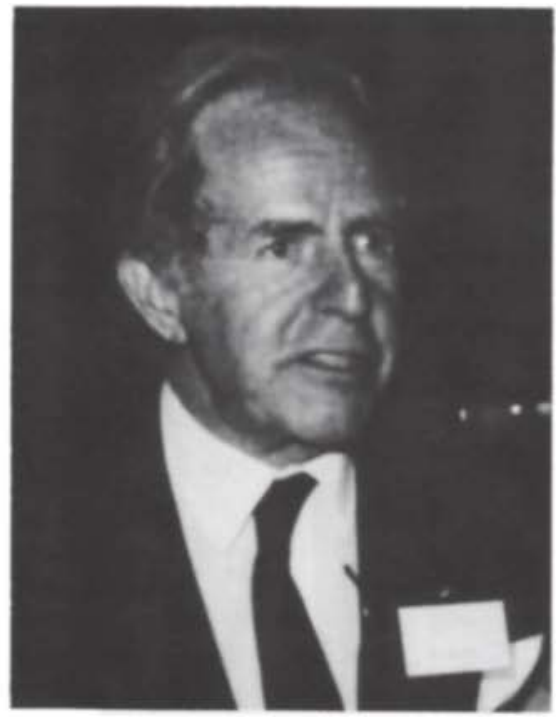

Pierre Lalive d'Epinay. Für seinen grundlegenden und originellen Beitrag zur Theorie des internationalen Privatrechts sowie für den Anstoß, den er mit seinem Unterricht, seinem Einsatz und seinen Schriften zu dessen Anwendung und Durchsetzung bei der Lösung der Probleme der heutigen, sich wandelnden Gesellschaften gegeben hat.

\section{Für Geophysik (Feste Erde)}

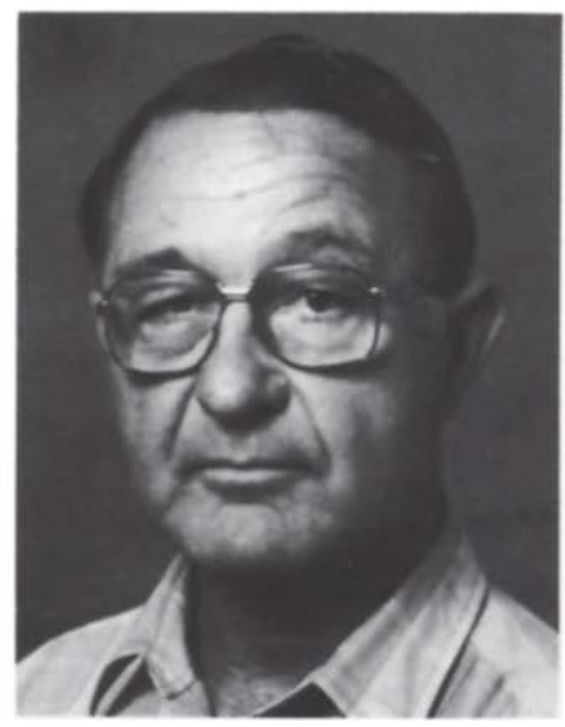

James Freeman Gilbert. Für seine herausragenden Beiträge zu unserer Kenntnis des tiefsten Erdinnern.

Verantwortlich für den Anzeigenteil: E. Lückermann, Heidelberger Platz 3, 1000 Berlin 33, Bundesrepublik Deutschland. - $\odot$ Springer-Verlag, Berlin-Heidelberg 1990. Springer-Verlag GmbH \& Co. KG, 1000 Berlin 33, Bundesrepublik Deutschland. - Satz: Mitterweger Werksatz GmbH, W-6831 Plankstadt, Bundesrepublik Deutschland. Druck: Druckhaus Beltz, W.6944 Hemsbach, Bundesrepublik Deutschland - Printed in Germany. 